\title{
EXTRAMEDULLARY HEMATOPOIESIS PRESENTING AS AN INTRAATRIAL MASS IN A PATIENT WITH CHRONIC MYELOGENOUS LEUKEMIA
}

\author{
Richard K. Freeman, MD, Frederick M. Howden, MD, Preston S. Gable, MD, and Kelly J. Bethel, MD, \\ San Diego, Calif.
}

Extramedullary hematopoiesis complicating myeloproliferative disorders is a common diagnosis at autopsy. It may involve any organ in patients with agnogenic myeloid metaplasia and less commonly polycythemia rubra vera or chronic myelogenous leukemia (CML). However, extramedullary hematopoiesis has been reported to involve the pericardium in only six cases, with no reports of myocardial involvement. We present the first known case of the resection of an intracardiac atrial mass in a patient with CML that on pathologic examination proved to be myocardium-based extramedullary hematopoiesis.

A 35-year-old African American woman originally received the diagnosis of Philadelphia chromosomepositive CML in 1988 and had done well receiving maintenance chemotherapy with hydroxyurea. In December 1992 she was admitted with a 48-hour history of fever and chills, nausea, malaise, and a nonproductive cough. The physical examination was remarkable for a heart rate of 120 beats $/ \mathrm{min}$ with a grade $2 / 6$ diastolic murmur and no pericardial rub. Jugular venous distention to $16 \mathrm{~cm}$ while upright was present, but not pulsus paradoxus. The chest roentgenogram on admission revealed an enlarged cardiac silhouette suggestive of a pericardial effusion and an electrocardiogram showed only sinus tachycardia. A transthoracic echocardiogram showed a small pericardial effusion and a $4 \mathrm{~cm}$ right intraatrial mass arising from the lower aspect of the atrial septum (Fig. 1). These findings were supported by a subsequent transesophageal echocardiogram, which showed the mass to be partially prolapsing through the tricuspid valve in diastole.

With the persistence of her symptoms, the patient was taken to the operating room and cardiopulmonary bypass was begun. Through a right atriotomy, a 5 by 4

From the Divisions of Thoracic Surgery and Hematology/Oncology and the Departments of Pathology and Clinical Investigation, Naval Medical Center, San Diego, Calif.

The Chief, Navy Bureau of Medicine and Surgery, Washington, D.C., Clinical Investigation Program sponsored this report No. 84-16-1068-439, as required by HSETCINST 6000.41A. The views expressed in this article are those of the authors and do not reflect the official policy or position of the Department of the Navy, the Department of Defense, or the United States Government.

J THORAC CARDIOvasc SURG 1995;110:552-4

12/54/62102 by $2 \mathrm{~cm}$ pedunculated mass was resected en bloc, including a $2 \mathrm{~cm}$ portion of atrial wall adjacent to the junction of the inferior vena cava with the right atrium. The atriotomy was closed and the patient was transferred to the intensive care unit. Her postoperative recovery was uneventful except for a superficial sternal wound infection. She was discharged from the hospital on postoperative day 17.

After a brief period of postoperative convalescence, the patient returned to full-time employment. Her CML entered an accelerated phase 6 months after the operation. Serial transthoracic echocardiogram showed no further abnormalities. She currently is doing well 2 years after the operation with maintenance chemotherapy while awaiting bone marrow transplantation.

Pathologic examination of the specimen revealed a portion of atrial septum with focal infiltration by granulocytic and erythroid precursors, as well as megakaryocytes. These were grossly evident as multiple yellow-tan nodules measuring up to $2 \mathrm{~mm}$ that were interdigitated between myocardial muscle fibers. No large aggregates of myeloblasts were identifiable. These findings were consistent with a diagnosis of myocardium-based extramedullary hematopoiesis (Fig. 2).

Extramedullary hematopoiesis is a widely recognized complication in patients with myeloproliferative disorders. The spleen, liver, lymph nodes, kidneys, and retroperitoneum are most commonly involved. ${ }^{1}$ In contrast to infiltrates or hemorrhages, extramedullary hematopoiesis involving the heart is rare. Among six case reports in the literature, five of the patients had agnogenic myeloid metaplasia and one had CML. ${ }^{2-7}$ In all six patients, the extramedullary hematopoiesis appeared confined to the pericardium, where a hemodynamically significant effusion was diagnosed and drained.

To our knowledge, this is the first reported case of extramedullary hematopoiesis involving the myocardium that was diagnosed before death and treated with surgical resection. This case illustrates the need for a collaborative approach to these patients. The surgeon and oncologist should consider the prognosis of the patient's underlying malignant disease, the degree of symptoms, and the level of relative immunocompetency when contemplating operative intervention in patients with disorders of myeloproliferation involving the heart. This case also emphasizes the need to broaden the differential diagnosis in patients with hematologic malignant disease to include extramedullary hematopoiesis as well as granulocytic sarcomas and leukemic cell infiltrates. 


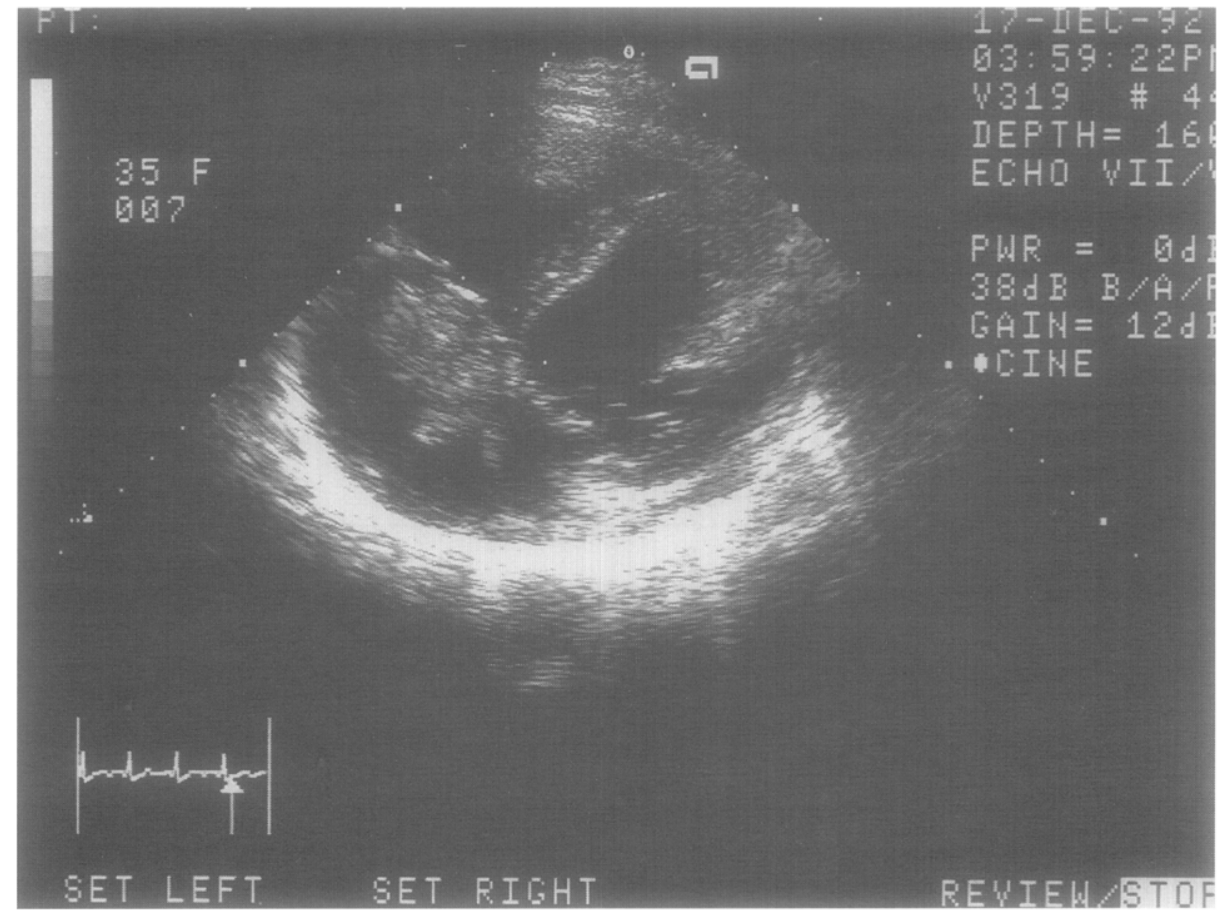

Fig. 1. Transthoracic echocardiography demonstrates a $4 \mathrm{~cm}$ right intraatrial mass arising from the atrial septum.

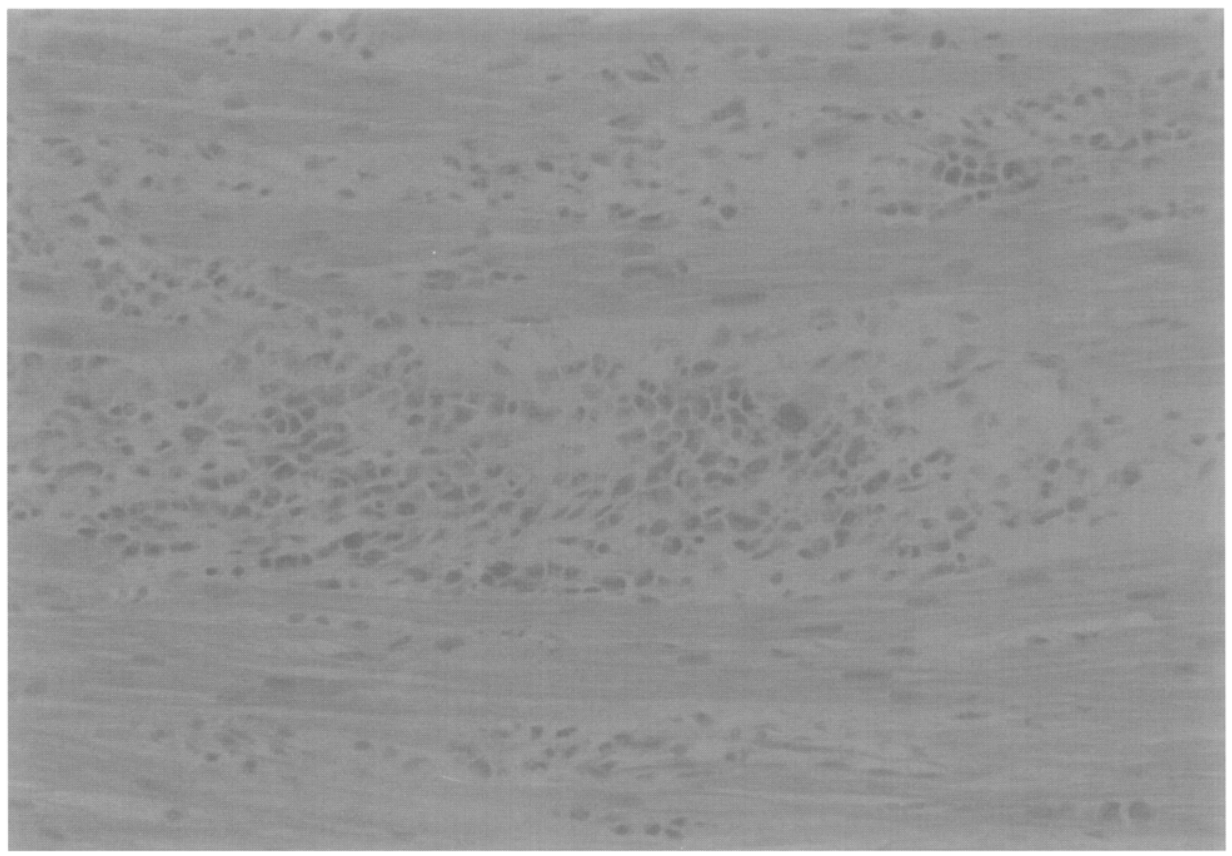

Fig. 2. Light microscopy: Extramedullary hematopoiesis is seen to interdigitate between myocardial muscle fibers (hematoxylin and eosin; original magnification $\times 140$ ). 


\section{REFERENCES}

1. Ward HP, Block MH. The natural history of agnogenic myeloid metaplasia and a critical evaluation of its relationship with the myelodysplastic syndrome. Medicine 1971;50:357-420.

2. Shih LY, Lin FC, Kuo TT. Cutaneous and pericardial extramedullary hematopoiesis with cardiac tamponade in chronic myeloid leukemia. Am J Clin Pathol 1988; 89:693-7.

3. Lewis TN, Klingerman MM. Pericardial and myocardial involvement by leukemias and lymphomas. Cancer 1970;25:1004-8.

4. Vilaseca J, Arnau JM, Tallada N, Bernardo L, Lopez-
Vivancos J, Guardia J. Agnogenic myeloid metaplasia presenting as massive pericardial effusion due to extramedullary hematopoiesis. Acta Haematol 1985;73: 239-40.

5. Pipoly GM, Rogers J. Cardiac tamponade resulting from pericardial extramedullary hematopoiesis. Cancer 1979;44:1504-6.

6. Bubley G, Come P, MacDougall D, Thurer R, Goldberg J. Pericardial tamponade associated with myeloid metaplasia. Am J Hematol 1983;14:185-8.

7. Haedersdal C, Hasselbalch H, Devantier A, Sounamaki K. Pericardial hematopoiesis with tamponade in myelofibrosis. Scand J Haematol 1985;34:270-3.

\section{PRIMARY AORTIC SARCOMA: RESECTION BY TOTAL ARCH REPLACEMENT}

Satoshi Sekine, MD, Tadaaki Abe, MD, Keiji Seki, MD, Yoshiki Shibata, MD, and Itsuro Yamagishi, MD, Akita, Japan

Because of the rarity and varying presentations of primary aortic tumors, antemortem diagnosis of these tumors is difficult. This report presents the case of a patient with primary aortic malignant hemangioendothelioma involving the aortic arch, which was resected with total arch replacement.

A 53-year-old woman was readmitted to Akita University Hospital with frequent recurrence of a low-grade fever. She had been well 6 months earlier after admission to this hospital with progressive general fatigue and a low-grade fever. During the first admission, no malignant disease was detected, and all tumor markers were within normal limits. A diagnosis of sacroiliac arthritis was made, and she was discharged home receiving a low dose of prednisolone (5 mg/day) and loxoprofen ( $180 \mathrm{mg} / \mathrm{day})$.

On physical examination at readmission to the hospital, she was pale and a systolic grade 2 murmur was noticed along the upper right sternal border and the neck. No other pathologic conditions were revealed. Laboratory examination showed the following values: hemoglobin 7.2 $\mathrm{gm} / \mathrm{dl}$, hematocrit $23.7 \%$, white blood cell count $16.9 \times$ $10^{3} / \mu \mathrm{l}$, erythrocyte sedimentation rate $165 \mathrm{~mm} / \mathrm{hr}$, and C-reactive protein $11.2 \mathrm{mg} / \mathrm{dl}$. Four days later, she had sudden cyanosis and numbness of the toes. The dorsal pedal pulses were present, and the ischemia improved within a day. Electrocardiography showed normal sinus rhythm and echocardiography showed no abnormalities in the heart. The aortitis syndrome was suspected and computed tomographic scanning of the chest was done, which

From the Department of Cardiovascular Surgery, Akita University School of Medicine, Akita 010, Japan.

J ThoraC CARDIOvasc SURg 1995;110:554-6

Copyright (C) 1995 by Mosby-Year Book, Inc.

$0022-5223 / 95 \$ 3.00+0 \quad \mathbf{1 2 / 5 4 / 6 1 7 1 4}$

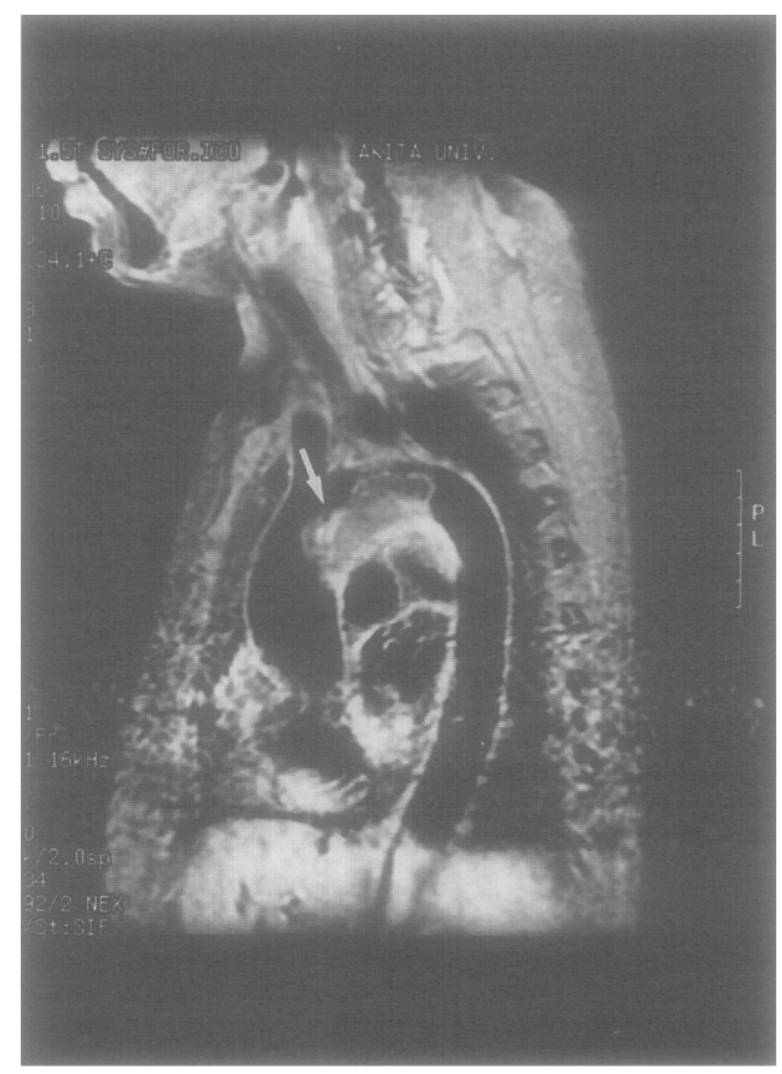

Fig. 1. MRI of chest demonstrates that tumor (arrow) arising from inferior surface of aortic arch occupies practically entire transverse aorta and part of ascending and descending arch of aorta. 